\title{
A Facile Approach for the Synthesis of Zinc Ferrite/Alkali Cellulose as an Effective Magnetic Photocatalyst for the Degradation of Methylene Blue in Aqueous Solution
}

\section{Khaled Charradi}

Borj Cedria Science and Technology Park: Technopole de Borj-Cedria

\section{Zakarya Ahmed}

Borj Cedria Science and Technology Park: Technopole de Borj-Cedria

\section{Mohamed Moussa}

Borj Cedria Science and Technology Park: Technopole de Borj-Cedria

\section{Zyed Beji}

Borj Cedria Science and Technology Park: Technopole de Borj-Cedria

\section{Ameni Brahmia}

King Khalid University

\section{Israa Othman}

Khalifa University of Science and Technology - Masdar City Campus

\section{Mohammad Abu Haija}

Khalifa University of Science and Technology - Masdar City Campus

\section{Radhouane Chtourou}

Borj Cedria Science and Technology Park: Technopole de Borj-Cedria

Sherif Keshk ( $\square$ keshksherif@gmail.com )

Technopole de Borj-Cedria https://orcid.org/0000-0002-0314-1891

\section{Research Article}

Keywords: Alkali cellulose, spinel zinc ferrite, methylene blue, photocatalytic degradation

Posted Date: March 3rd, 2021

DOl: https://doi.org/10.21203/rs.3.rs-260470/v1

License: (c) (i) This work is licensed under a Creative Commons Attribution 4.0 International License. Read Full License 


\section{Abstract}

The spinel zinc ferrite/alkali cellulose composite has been successfully fabricated as a magnetic photocatalyst and assessed for its photocatalytic activity toward the degradation of methylene blue (MB) in an aqueous solution. The Fourier transform infrared (FTIR) spectroscopy, X-ray diffraction (XRD), scanning electron microscopy (SEM), energy-dispersive X-ray (EDX), thermogravimetric analysis (TGA), $\mathrm{BET}$, and zeta potential were used to evaluate the magnetic photocatalyst composite and investigate its adsorption mechanism. Furthermore, the adsorption behavior of the composite was studied under various conditions. The $\mathrm{ZnFe}_{2} \mathrm{O}_{4}$ /alkali cellulose composite effectively degraded (100\%) MB after 180 min at a pH of 6.5 compared to cellulose, alkali cellulose and $\mathrm{ZnFe}_{2} \mathrm{O}_{4}$. The regeneration of the loaded composite was studied using the alcohol/water solution and reused upon a certain variation in the efficiency after the fourth cycle. The adsorption process was found to be consistent with the pseudosecond-order kinetic model.

\section{Introduction}

High efficiency photocatalysts have been extensively studied due to their potential applications in the decomposition of toxic compounds as well as the rapid progress of modern industry (Sulaiman et al., 2016; Abboud et al., 2020). Besides, heavy metals and dyes are the most toxic effluents present in industrial wastewater, even at low concentrations. Numerous dyes are produced from different chemical industries, such as dye manufacturing, textile, paper and pulp, plastic, pharmaceutical, tanneries, cosmetics, and food processing (Bhattacharyya et al., 2015). Various treatment procedures have been described in the last three decades to remove dyes from wastewater, such as adsorption, membrane filtration, coagulation-flocculation, chemical oxidation, sedimentation, and photodegradation (Abboud et al., 2020). Among these procedures, photocatalysis is considered to be the most promising and frequently used technique due to its simplicity, short reaction time, high oxidation power, reduced energy consumption, ability to remove a wide variety of dyes, and eco-friendly nature. The mechanism of photocatalysis involves UV-vis irradiation of a semiconductor compound such as $\mathrm{TiO}_{2}, \mathrm{ZnO}_{2} \mathrm{Fe}_{2} \mathrm{O}_{3}, \mathrm{CdS}_{\text {, }}$ and $\mathrm{ZnS}$ as a catalyst then, electron excitation from the valence band to the conduction band (Cao et al., 2018; Wang et al., 2018). However, there was remarkable progress in the development of photocatalysis in the ultraviolet (UV) region compared to those in the visible light region. The development of visible light photocatalysts is one of the most significant photocatalytic research in recent years. Titania $\left(\mathrm{TiO}_{2}\right)$ shows high photoactivity under UV light illumination, while zinc ferrite $\left(\mathrm{ZnFe}_{2} \mathrm{O}_{4}\right)$ is sensitive to apparent light. $\mathrm{ZnFe}_{2} \mathrm{O}_{4}$ cannot be utilized directly for the photocatalytic degradation of organic pollutants due to its low valence band potential and poor photoelectric conversion between zinc and iron (Valenzuela et al., 2002). $\mathrm{TiO}_{2} / \mathrm{ZnFe}_{2} \mathrm{O}_{4}$ photocatalyst was synthesized via liquid catalytic phase conversion and sol-gel method (Jang et al., 2009; Xu et al., 2009). The presence of $\mathrm{ZnFe}_{2} \mathrm{O}_{4}$ effectively improved the photodegradation of methyl orange under visible light irradiation (Arimi et al., 2018). $\mathrm{BiFeO}_{3} / \mathrm{ZnFe}_{2} \mathrm{O}_{4}$ composite was prepared via a glyoxylate precursor method using a two-pot approach (Safizade et al., 2018). Owing to the synergic effect between $\mathrm{BiFeO}_{3}$ and $\mathrm{ZnFe}_{2} \mathrm{O}_{4}$, the composite containing $25 \mathrm{wt} \%$ of 
$\mathrm{ZnFe}_{2} \mathrm{O}_{4}$ displayed the highest efficiency for the photodegradation of methylene blue under visible light (Safizade et al., 2018). Furthermore, Yttrium (Y) doped copper and zinc ferrite composites are fabricated by the solution combustion method. The resultant yttrium/zinc ferrite composite showed the highest photocatalytic activity of $94 \%$ in 180 min for the degradation of methylene blue dye as well as $\mathrm{Mg} / \mathrm{Mn}$ substituted Ni/zinc ferrite composites (Ajithkumar et al., 2020). Due to the effective separation and delayed recombination of e-h pairs in ferrites, the charge carriers facilitate the oxidation of the methylene blue in solution (George et al., 2020). Consequently, the photocatalytic process requires the absorption of visible light from solar or artificial sources (Salvetatu et al., 1999). The use of multi-walled carbon nanotubes (MWCNTs) as a reaction component in the synthesis of photocatalysts improves the photocatalytic activity of the ferrites to efficiently absorb visible light (Oh et al., 2008). $\mathrm{ZnFe}_{2} \mathrm{O}_{4} / \mathrm{MWCNT}$ composite was synthesized using the arc discharge method. Its photocatalytic activity toward the degradation of methylene blue showed that $84 \%$ degradation was found to result in the presence of zinc ferrite photocatalyst, while $99 \%$ degradation was observed in the composite after irradiation for $5 \mathrm{~h}$ under visible light (Singhal et al., 2013). Therefore, MWCNTs play an important role as an organic component in improving the structural properties of zinc ferrite. In our previous work, alkali cellulose $\left(\mathrm{C}_{6} \mathrm{H}_{10} \mathrm{O}_{5} \star \mathrm{NaOH}\right)$ obtained via the treatment of cellulose with aqueous sodium hydroxide displayed a wide range of applications in food and pharmaceutical processes (Keshk et al., 2015, 2018; Keshk \& Hamdy 2019; Elkott A. et al., 2019; Marzouki et al., 2019; 2021) due to its properties, such as electrical properties, colorlessness, non-toxicity, high adsorption capacity, optimal mechanical strength, relatively optimal adsorption, cost efficiency and availability. In this work, alkali cellulose was used as an effective biotemplate reactor for the dispersion of $\mathrm{ZnFe}_{2} \mathrm{O}_{4}$ nanostructure through the porous structure of alkali cellulose for the first time. Thus, facile fabrication of $\mathrm{ZnFe}_{2} \mathrm{O}_{4} /$ alkali cellulose composite without any spacers was reported. Moreover, the photocatalytic activity of $\mathrm{ZnFe}_{2} \mathrm{O}_{4} /\left(\mathrm{C}_{6} \mathrm{H}_{10} \mathrm{O}_{5}{ }^{*} \mathrm{NaOH}\right)_{n}$ was investigated using methylene blue (MB) as a toxic organic pollutant.

\section{Materials And Methods}

The cellulose powder used in the study was supplied by Sigma-Aldrich. All the reagents were purchased from Sigma-Aldrich and used as received.

\section{Preparation of alkali cellulose $\left(\mathrm{C}_{6} \mathrm{H}_{10} \mathrm{O}_{5} * \mathrm{NaOH}\right)_{n}$}

Cellulose powder $(1.0 \mathrm{~g})$ was dopped in $\mathrm{NaOH}$ solution $(2.0 \mathrm{M})$ at room temperature for $3 \mathrm{~h}$. The alkali sample was collected by filtration without further washing and labeled as "alkali-cellulose" $\mathrm{C}_{6} \mathrm{H}_{10} \mathrm{O}_{5}$ * $\mathrm{NaOH}$ (Marzouki et al., 2019).

\section{Preparation of Zinc ferrite/alkali cellulose composite}

Stoichiometric amounts of $\mathrm{FeCl}_{3}(0.68 \mathrm{~g})$ and $\mathrm{ZnCl}_{2}(1.62 \mathrm{~g})$ were dissolved in $100 \mathrm{ml}$ deionized water. Alkali cellulose $(1 \mathrm{~g})$ was added to the above solution and stirred vigorously at $60{ }^{\circ} \mathrm{C}$. Subsequently, $6 \mathrm{~g}$ of 
$\mathrm{NaOH}$ was added to the mixture gradually within an hour to obtain a yellow wish brown precipitate under a pH of 12. The obtained yellow wish brown powder was placed in an oven under $110^{\circ} \mathrm{C}$ for $6 \mathrm{~h}$. The resultant composite was washed several times with distilled water and ethanol and dried at $60{ }^{\circ} \mathrm{C}$ for 48 h.

\section{Characterization of the crystal structure and morphology}

The Fourier-transform infrared (FT-IR) spectra of zinc ferrite and alkali cellulose were measured at room temperature using the Bruker FT-IR IFS 66 spectrophotometer over the range of $500-4000 \mathrm{~cm}^{-1}$.

The X-Ray Diffraction (XRD) analysis was performed at room temperature using the Shimadzu L ab XRD6000 with CuKa radiation of $1.54 \AA$ and a secondary monochromator. The XRD tube was operated at a voltage of $30 \mathrm{kV}$ and a current of $30 \mathrm{~mA}$ in the $2 \theta$ range from $10^{\circ}$ to $60^{\circ}$.

The morphology of the sample was evaluated using the scanning electron microscopy FEG QUANTA 250 operated at $30 \mathrm{kV}$ and equipped with an energy-dispersive X-ray instrument (EDX) for elemental analysis. The surface morphology and particle distribution of the samples were assigned using the FEI Tecnai 20 instrument operated at $200 \mathrm{kV}$.

The size distribution was determined by studying the TEM images recorded using the Tecnai 20-Philips instrument $(G 20,200 \mathrm{kV})$. The powder samples were ultrasonically dispersed in ethanol.

The surface area and porosity analysis were conducted using the Novo 2000e Quanta chrome. The sample was degassed at $95^{\circ} \mathrm{C}$ overnight prior to the $\mathrm{N}_{2}$ adsorption experiment. The specific surface area was determined by the Brunauer-Emmett-Teller (BET) model, while the pore volumes and pore radii were determined by the Barrett-Joyner-Halenda (BJH) model.

The thermogravimetric analysis (TGA) was evaluated using the Shimadzu TGA60 under $\mathrm{N}_{2}$ atmosphere with a heating rate of $10^{\circ} \mathrm{C} \mathrm{min}{ }^{-1}$.

The size and zeta potential of different particles dispersed in water were determined by the Zetasizer Nano ZS (Malvern Paralytical).

\section{Evaluation of photocatalytic degradation}

The photocatalytic degradation of $\mathrm{ZnFe}_{2} \mathrm{O}_{4}$ /alkali cellulose composite was performed by the degradation of $\mathrm{MB}$ as a model of the organic pollutants in an aqueous solution. Typically, $50 \mathrm{mg}$ of the composite was dipped in $10 \mathrm{mg} \mathrm{L}^{-1}$ of $\mathrm{MB}(200 \mathrm{~mL})$. The solution mixture was subjected to sunlight for $3 \mathrm{~h}$ and gathered at regular time intervals during irradiation to evaluate the photocatalytic degradation. The concentration of MB was evaluated by recording its absorbance at a wavelength of $664 \mathrm{~nm}$ using a UVvis spectrophotometer (Analytik Jena, Germany) in order to determine the photodegradation efficiency. 
The UV-vis spectra were recorded at room temperature over a wavelength of $200 \mathrm{~nm}$ to $800 \mathrm{~nm}$. The photodegradation percentage of $\mathrm{MB}$ in the aqueous solution was determined as follows:

$\left(\mathrm{C}_{0}-\mathrm{C}_{\mathrm{t}}\right) / \mathrm{C}_{0} \quad \mathrm{X} 100$

where $\mathrm{C}_{0}$ is the initial concentration, and $\mathrm{C}_{\mathrm{t}}$ is the concentration at a certain time interval.

\subsection{Kinetics of the photocatalytic degradation of $\mathrm{MB}$ by the $\mathrm{ZnFe}_{2} \mathrm{O}_{4} /$ alkali cellulose}

The degradation reactions were found to be zero-order, pseudo-first order, and pseudo-second-order equations as listed below:

$$
\begin{aligned}
& \mathrm{C}_{\mathrm{t}}=-\mathrm{k}_{\mathrm{t}}+\mathrm{C}_{0} \\
& \ln \frac{C_{t}}{C_{o}}=-k t \\
& \frac{1}{C_{t}}=k t+\frac{1}{C_{o}}
\end{aligned}
$$

where $\mathrm{C}_{\mathrm{o}}$ and $\mathrm{C}_{\mathrm{t}}$ are the initial and residual concentrations of $\mathrm{MB}$ after a specific time of the reaction. $k_{t}$ is the rate constant of the superficial reaction obtained from the plots of the equations.

\section{Reusability and chemical stability of the composite}

Reusability is a key factor for the practical application of the composite. Therefore, the reusability of the $\mathrm{ZnFe}_{2} \mathrm{O}_{4}$ /alkali cellulose photocatalyst for the photocatalytic degradation of MB was evaluated in four runs. After each run, the $\mathrm{ZnFe}_{2} \mathrm{O}_{4}$ /alkali cellulose was separated by an external magnetic field, washed with alcohol/water, dried at $100{ }^{\circ} \mathrm{C}$, and reused thereafter. Finally, the chemical stability of the $\mathrm{ZnFe}_{2} \mathrm{O}_{4}$ /alkali cellulose was investigated after the fourth recovery run via XRD analysis.

\section{Results And Discussion}

Under concentrated alkaline solutions, physicochemical and structural modifications of cellulose were found to take place. Native cellulose (Cellulose I) was treated with concentrated sodium hydroxide to form alkali cellulose. As a result of the penetration of the alkali onto the lattice, internal hydrogen bonds were broken, and the number of available hydroxyl groups $(-\mathrm{OH})$ was increased by around $25 \%$ (Marzouki et al., 2019). Thus, zinc ferrite interacted effectively with alkali cellulose rather than pristine cellulose.

\section{Characterization and analysis of the composite}


The FT-IR spectrum of alkali cellulose (Fig.1) revealed the breaking of intermolecular hydrogen bonds characteristic of the- $\mathrm{OH}$ group and displayed a broad band at the region of $3320 \mathrm{~cm}^{-1}$ corresponding to the $\mathrm{OH}$ stretching vibration that was attributed to the intramolecular hydrogen bonds (Marzouki et al., 2019). Furthermore, the $\mathrm{C}-\mathrm{OH} . . . \mathrm{NaOH}$ feature, i.e., the activated hydroxyl group in $\mathrm{C} 6 \mathrm{H} 1005^{\star} \mathrm{NaOH}$, appeared as a weak band in the region about $1023 \mathrm{~cm}^{-1}$ (Marzouki et al., 2019). On the other hand, a decrease in the band intensity of the methylene group at $2877 \mathrm{~cm}^{-1}$ was observed in the spectrum of $\mathrm{ZnFe}_{2} \mathrm{O}_{4}$ /alkali cellulose composite that confirmed the presence of $\mathrm{ZnFe}_{2} \mathrm{O}_{4}$ in the network of alkali cellulose. The $\mathrm{OH}$ stretching vibration was associated with the water molecules coordinated to the ferrite structure and its deformation, which were observed at $3428 \mathrm{~cm}^{-1}$ and $1693 \mathrm{~cm}^{-1}$, respectively.

The presence of zinc ferrite in the composite was confirmed by the strong stretching vibration bands of $\mathrm{Zn}-0-\mathrm{Fe}$ at $1453 \mathrm{~cm}^{-1}$ (Patil et al., 2013). Furthermore, the weak bands appearing at $425 \mathrm{~cm}^{-1}$ and 570 $\mathrm{cm}^{-1}$ represented tetrahedral and octahedral modes of $\mathrm{ZnFe}_{2} \mathrm{O}_{4}$, which were assigned to the $\mathrm{Fe}-\mathrm{O}$ and $\mathrm{Zn}-\mathrm{O}$ vibrations, respectively (Shahnavaz et al., 2014). The existence of these characteristic peaks confirmed the strong interaction between spinel $\mathrm{ZnFe}_{2} \mathrm{O}_{4}$ and alkali cellulose matrix forming the composite.

\section{X-ray diffraction (XRD)}

The XRD diffractogram of alkali cellulose displayed the typical diffraction peaks of the crystalline structure of cellulose II at $2 \theta$ values of $11.8^{\circ}, 12.3^{\circ}, 20.1^{\circ}$, and $21.7^{\circ}$ corresponding to the ( ), (110), (102) and (200) planes, respectively (Fig. 2) (Marzouki et al., 2019). The XRD pattern of the zinc ferrite/alkali cellulose composite was distinctly different from that of alkali cellulose.

The diffraction plane of alkali cellulose at the low angle side $\left(2 \theta=11.8^{\circ}\right)$ disappeared on incorporating zinc ferrite between the cellulose sheets corresponding to the $\left(1^{-} 10\right)$ plane at the $2 \theta$ value of $11.8^{\circ}$ parallel to the surface. Moreover, the observed broad reflection peaks of alkali cellulose may be attributed to the interaction of $\mathrm{ZnFe}_{2} \mathrm{O}_{4}$ particles with $\mathrm{ZnFe}_{2} \mathrm{O}_{4}$ nanoparticles. The diffraction peaks of $\mathrm{ZnFe}_{2} \mathrm{O}_{4}$ were observed at the $2 \theta$ values of $30.1^{\circ}, 33.0^{\circ}, 35.3^{\circ}, 38.0^{\circ}, 41.4^{\circ}, 46.5^{\circ}$, and $48.3^{\circ}$ corresponding to the reflection patterns of (220), (311), (222), (400), (422), (511), and (440), respectively, indicating the presence of a spinel cubic structure (Kumar et al., 2018). These results indicated the interaction of $\mathrm{ZnFe}_{2} \mathrm{O}_{4}$ with alkali cellulose, owing to the breakage of intermolecular hydrogen bonds as well as the presence of sodium ion in alkali cellulose that facilitated its interaction with $\mathrm{ZnFe}_{2} \mathrm{O}_{4}$ rather than with pristine cellulose.

\section{Field emission scanning electron microscopy (FESEM)}

The scanning electron microscopy (SEM) image of alkali cellulose and its ferrite composite are shown in Fig. 3. As can be seen from Fig.3b, the surface of the composite was composed of cylindrical aggregates of uniform $\mathrm{ZnFe}_{2} \mathrm{O}_{4}$ nanosheets distributed among the cellulosic fibers containing several voids that indicated the high porosity and resistivity of the composite. 
The void plays a definite role in the diametric swelling of the composite. Also, the cylindrical structure contributed to an increase in the tensile strength (high mechanical stability) of the composite. However, the presence of these elongated voids did not result in an asymmetric extension under stress within the composite. The EDX spectra exhibited different intense peaks associated with $\mathrm{Zn}, \mathrm{Fe}, \mathrm{O}$, and $\mathrm{C}$ atoms, indicating that a highly pure composite was formed without residual side products.

\section{High-resolution transmission electron microscopy (HRTEM)}

To further confirm the interaction between $\mathrm{ZnFe}_{2} \mathrm{O}_{4}$ and cellulose in the composite, the micrograph of the $\mathrm{ZnFe}_{2} \mathrm{O}_{4}$ /alkali cellulose was investigated by TEM. The HRTEM images of the $\mathrm{ZnFe}_{2} \mathrm{O}_{4} /$ alkali cellulose under different magnifications are presented in Fig.4. The micro images suggest that the $\mathrm{ZnFe}_{2} \mathrm{O}_{4}$ nanoparticles were successfully supported on the alkali cellulose. The $\mathrm{ZnFe}_{2} \mathrm{O}_{4}$ nanoparticles exhibited spherical particles ranging from 4 to $8 \mathrm{~nm}$. It is worth mentioning that the nanoparticles showed some agglomeration, which is attributed to their small particle size and absence of steric hindrance (Tedjieukeng H.M. K. et al 2018). The average d-spacing of the observed lattice fringes was around 0.26 $\mathrm{nm}$, which was assigned to the (311) plane of $\mathrm{ZnFe}_{2} \mathrm{O}_{4}$. The size of the obtained crystallite from the analysis of TEM images was in good agreement with that determined by the Debye-Scherrer approximation.

The crystallite sizes were obtained from the analysis of TEM images and were consistent with the zeta potential and investigation of particle size (Table 3).

\section{Thermogravimetric analysis (TGA)}

The thermal stability of cellulose, alkali cellulose, and its composite were analyzed under air conditions at a heating rate of $5{ }^{\circ} \mathrm{C} / \mathrm{min}$. The TGA curve in Fig. 5 showed that the decomposition temperature of alkali cellulose was higher than that of cellulose, owing to the deformation in the crystal structure of cellulose (by breaking the hydrogen bond).

Furthermore, a small weight loss was observed at about $150{ }^{\circ} \mathrm{C}$ due to the evaporation of residual water from cellulose and alkali cellulose. A major weight loss (second weight loss) was observed at about 300 ${ }^{\circ} \mathrm{C}$ for alkali cellulose and $350{ }^{\circ} \mathrm{C}$ for cellulose, which was attributed to the degradation of lignin. On comparing alkali cellulose and composite, the behavior was found to be different, where the first and second weight losses for the composite were shifted to higher values, indicating a good interaction between zinc ferrite and alkali cellulose matrix that enhanced its thermal stability.

The weight loss percentage at both $300{ }^{\circ} \mathrm{C}$ and $600^{\circ} \mathrm{C}$ indicated that the $\mathrm{Zn}$ ions in $\mathrm{ZnFe}_{2} \mathrm{O}_{4}$ were incorporated into the sodium cellulose (alkali cellulose) matrix and formed strong linkage bonds with higher binding energy, glass transition temperature, and thermal stability during the fabrication process. These data were consistent with the published data on $\mathrm{ZnO}$ /alkali cellulose composite (Keshk \& Hamdy, 2018) 


\section{Brunauer-Emmett-Teller (BET) analysis of the surface area}

The textural properties of the photocatalyst were characterized by the BET analysis. Fig. 6 shows the $\mathrm{N}_{2}$ adsorption-desorption isotherm of the $\mathrm{ZnFe}_{2} \mathrm{O}_{4}$ /alkali cellulose that is characterized as the type- $\mathrm{V}$ isotherm.

The estimated BET specific surface area was $5.3 \mathrm{~m}^{2} / \mathrm{g}$, with a total pore volume of $0.028 \mathrm{~cm}^{3} / \mathrm{g}$. Using the Barrett-Joyner-Halenda (BJH) method, the pore radius values were found in the range of 0.2-3.5 $\mathrm{nm}$, indicating that the composite was composed of microporous and mesoporous structures (Groen et al., 2003).

\section{Photocatalytic activity of the magnetic photocatalyst}

Fig. 7 shows the UV-vis absorbance of methylene blue in the reaction system after a specific time interval. The structure of MB contains phenothiazine and dimethylamine on each side. The zinc ferrite-based photocatalyst recombined with alkali cellulose showed relatively high degradation potential (Fig. 7). The surface charge of $\mathrm{ZnFe}_{2} \mathrm{O}_{4}$ /alkali cellulose facilitated the interaction between the composite and $\mathrm{MB}$, as indicated by the zeta potential and particle size investigation (Table 3).

The photocatalytic activity of the composite depends on its composition, specific surface area, porosity, size, distribution of particles, and nature of the crystalline phase. The $\mathrm{ZnFe}_{2} \mathrm{O}_{4} /$ alkali cellulose achieved complete degradation of $\mathrm{MB}(100 \%)$ within $3 \mathrm{~h}$, whereas $\mathrm{ZnFe}_{2} \mathrm{O}_{4}$ /cellulose showed low efficiency $(60 \%)$. The effect of $\mathrm{pH}$ of the reaction on the degradation of $\mathrm{MB}$ was shown in Fig. (8).

The degradation of methylene blue increased gradually as the $\mathrm{pH}$ increased from 4 to 6.5 . Thereafter, a noticeable decrease in degradation was observed for the $\mathrm{pH}$ values from 6.5 to 9 . Methylene blue was protonated in the acidic medium and excess $\mathrm{H}^{+}$ions bonded with the $\mathrm{OH}$ group, which consequently reduced the degradation of the dye. Furthermore, the dye was deprotonated in the alkaline medium, resulting in repulsion between the surface of the adsorbent and dye. Therefore, all the experiments were conducted at a pH of 6.5 as it showed the best results. The observed trend was in agreement with the previously reported results in the literature (Nasrullah A. et al 2018) (Liu Y. et al 2018). The degradation data were fitted to the zero-order, pseudo-first order, and pseudo-second-order equations. The obtained $\mathrm{k}$ values are listed in Table 1. Accordingly, the data for both catalysts were consistent with the pseudosecond-order kinetics.

Table 1 Comparison of various kinetic models 


\begin{tabular}{|lllll|}
\hline Rate equation & \multicolumn{2}{l}{$\mathrm{ZnFe}_{2} \mathrm{O}_{4}$ /cellulose } & \multicolumn{2}{l|}{$\mathrm{ZnFe}_{2} \mathrm{O}_{\mathbf{4}}$ /alkali cellulose } \\
\cline { 2 - 5 } & $\mathrm{K}$ & $\mathrm{R}^{2}$ & $\mathbf{k}$ & $\mathrm{R}^{2}$ \\
\hline Zero order & 0.0145 & 0.8539 & 0.0163 & 0.6295 \\
\hline Pseudo first order & 0.0104 & 0.9592 & 0.0155 & 0.8185 \\
\hline Pseudo second order & 0.0085 & 0.9711 & 0.0205 & 0.9744 \\
\hline
\end{tabular}

The effect of the catalyst loading in the range of $10-100 \mathrm{mg}$ on the photocatalytic degradation of $200 \mathrm{ml}$ of $10 \mathrm{mg} \mathrm{L}^{-1} \mathrm{MB}$ was evaluated. Accordingly, the degradation of $\mathrm{MB}$ by the $\mathrm{ZnFe}_{2} \mathrm{O}_{4} /$ alkali cellulose composite increased from $30 \%$ to $98 \%$ as the dosage of the catalyst increased from $10 \mathrm{mg}$ to $50 \mathrm{mg}$. However, any further increase in the catalyst loading resulted in a slight decrease in its performance. This could be attributed to the increase in the agglomeration of the catalyst induced by the increase in its loading, which consequently reduced its surface area and number of active sites involved in the photocatalytic reaction and therefore decreased the percentage of degradation (Mohamed R.M. et al 2012).. In addition, the increase in the amount of suspended particles induced the scattering of light and reduced the light transmittance through the system (Mohamed R.M. et al 2012, Paul D.R. et al 2019). The obtained results indicated that $50 \mathrm{mg}$ was the optimal mass of the catalyst under the specified reaction conditions. Furthermore, the zeta potential and particle size of the alkali cellulose and its composite were determined in water after $2 \mathrm{~h}$ of agitation. The particle size of $\mathrm{ZnFe}_{2} \mathrm{O}_{4}$, cellulose, and alkali cellulose varied between 105 to $180 \mathrm{~nm}$ under minimum charges (Table 2).

Table2 Particle size and Zeta potential

\begin{tabular}{|lll|}
\hline Sample & Particle size $(\mathrm{nm})$ & Zeta potential $(\mathrm{mV})$ \\
\hline $\mathrm{MB}$ & 10 & -5.01 \\
\hline $\mathrm{ZnFe}_{2} \mathrm{O}_{4}$ & 105 & +21.5 \\
\hline Cellulose & 115 & -18 \\
\hline Alkali-cellulose & 180 & -2.1 \\
\hline $\mathrm{ZnFe}_{2} \mathrm{O}_{4}$-Alkali-Cellulose & 970 & +19 \\
\hline
\end{tabular}

From Table 2, $\mathrm{ZnFe}_{2} \mathrm{O}_{4}$ /alkali cellulose composite was found to be the most effective catalyst for the degradation of $\mathrm{MB}$ compared to cellulose, alkali cellulose, or $\mathrm{ZnFe}_{2} \mathrm{O}_{4}$ due to the maximum particle size of the composite $(970 \mathrm{~nm})$ and a higher positive charge $(19 \mathrm{mV})$ than that observed in MB $(-5.01 \mathrm{mV})$. Moreover, the reusability and chemical stability results indicated that the $\mathrm{ZnFe}_{2} \mathrm{O}_{4}$ /alkali cellulose was easily regenerated and still showed good chemical stability after being reused for four cycles, suggesting its potential for industrial applications. 


\section{Conclusion}

A new magnetic $\mathrm{ZnFe}_{2} \mathrm{O}_{4}$ /alkali cellulose was synthesized as a photocatalyst via a facile approach. The characterization of the composite was performed using FT-IR, XRD, FESEM, EDS, TEM, BET, zeta potential, and UV techniques that confirmed the presence of spinel ferrites in the alkaline cellulose matrix. The photocatalytic experiments indicated that the composite was photo catalytically active. The degradation efficiency of this method increased with the photocatalyst dosage and irradiation time and decreased under alkaline and acidic $\mathrm{pH}$ values. The optimum conditions for the maximum degradation efficiency were a $\mathrm{pH}$ value of 7 , initial $\mathrm{MB}$ concentration of $2 \mathrm{mg} / \mathrm{mL}$, photocatalyst mass of $50 \mathrm{mg}$, and irradiation time of $180 \mathrm{~min}$. The $\mathrm{ZnFe}_{2} \mathrm{O}_{4}$ /alkali cellulose was easily separated using a magnet and regenerated without any significant loss of the photocatalytic activity after being used for four consecutive cycles. After the fourth regeneration cycle, the prepared composite showed good chemical stability and reusability. The degradation of MB was found to be $80 \%$ in the fourth cycle. The kinetic study of the process showed that the photocatalytic degradation of $M B$ followed pseudo-second-order kinetics $\left(\mathrm{R}^{2}=\right.$ 0.9744). Therefore, it is concluded that the developed biocomposite has a high potential for the degradation of MB from aqueous solutions and thus utilized as an appropriate photocatalyst with high efficiency, cost-effectiveness, easy operation, and simple preparation.

\section{Declarations}

Acknowledgments The authors extend their appreciation to the Deanship of Scientific Research at King Khalid University for funding this work.

Funding This research was supported by grant from Deanship of Scientific Research at King Khalid University through the project research program under number R.G.P 1/260/42.

\section{Compliance with ethical standards}

Conflict of interest The authors of this study verify that there are no conflicts of interest relating to the publication of this manuscript.

Ethics approval This article does not contain any studies with human participants or animals performed by any of the authors.

\section{References}

Abboud M, Sahlabji T, Abu Haija M, Bondock S, Ismail I, \& Keshk S M A S (2020) Synthesis and characterization of lignosulfonate/amino-functionalized SBA-15 nanocomposite for the adsorption of methylene blue from wastewater. New Journal Chemistry, 44: 2291-2302.

Ajithkumar P, Mohana S, \& Sumathi S, (2020) Synthesis characterization, optical and photocatalytic activity of yttrium and copper co-doped zinc ferrite under visible light. Journal of Materials Science: 
Materials in Electronics 31: 1168-1182.

Alrumman S, El-kott A \& Keshk S M A S (2016) Water Pollution: Source \& Treatment. American Journal of Environmental Engineering 6: 88-98.

Arsou A, Lena M, Luis I, G, Ralf D \& Detlef W B (2018) Visible-Light Photocatalytic Activity of Zinc Ferrites. Journal of Photochemistry and Photobiology A: Chemistry 366: 118-126.

Bhattacharya R \& Ray S K (2015) Removal of congo red and methyl violet from water using nano clay filled composite hydrogels of poly acrylic acid and polyethylene glycol. Chemical Engineering Journal 260: 269-283.

El-kott A, Syef A F, Sahar M A, Al Dessouky S \& Keshk S M A S (2019) Suppression Efficacy of Lignosulfonate/Mercerized Cotton Composite Against Cancer Cell's Activities. Advanced composite letter 28:1-9.

George L, Viji C, Maheen M, \& Mohammed E M (2020) Synthesis, characterization of Mg/Mn substituted $\mathrm{Ni}-\mathrm{Zn}$ ferrites and mechanism of their visible light photo catalysis of Methylene Blue and Rhodamine B dyes under magnetic influence. Material Resources Express 7: 015014.

Groen J C, Peffer LAA, Pérez-Ramírez J (2003) Pore size determination in modified micro- and mesoporous materials. Pitfalls and limitations in gas adsorption data analysis, Microporous and Mesoporous Materials 60: 1-17

Jang J S, Hong S J \& Lee J S (2009) Synthesis of Zinc Ferrite and Its Photocatalytic Application under Visible Light. Journal of the Korean Physical Society 54: 204-208.

Keshk S M A S, Hamdy S M \& Badr I H A (2015) Physicochemical Characterization of Mercerized Cellulose/ $\mathrm{TiO}_{2}$ Nanocomposite. American Journal of Polymer Science 5: 24-29.

Keshk SMAS, Aishah FA, El Zahhar A, Yousef S, Bondok S (2018) Physicochemical characterization of calcium lignosulfonate/sodium cellulose composite as food packing film. Transylvanian Review 16: 7609-7619.

Keshk S M A S \& Hamdy M (2019) Preparation and characterization of Zinc oxide/sodium cellulose composite for food packaging. Turkish Journal of Chemistry 43: 94-105.

Krogman K C, Zacharia N S, Grillo D M, Hammond P T (2008) photocatalytic layer by layer coatings for degradation of acutely toxic agents. Chemical Material 20: 1924-1930.

Kumar M, Singh Dosanjh H, Singh H (2018) Magnetic Zinc Ferrite-Chitosan Bio-Composite: Synthesis, Characterization and Adsorption Behavior Studies for Cationic Dyes in Single and Binary Systems. Journal of Inorganic and Organometallic Polymers and Materials 28: 880-898. 
Liu Y, Zheng Y A, \& Wang A Q (2010) Enhanced adsorption of Methylene Blue from aqueous solution by chitosan-g-poly (acrylic acid)/vermiculite hydrogel composites. Journal of Environmental Sciences 22: 486-493.

Marzouki R, Bondock S, Brahmi A, Keshk SMAS, Faouzi M, Koschell A, Heinze T (2019) Mercerization effect on structure and electrical properties of cellulose: development of a novel fast $\mathrm{Na}$-ionic conductor. Carbohydrate Polymers 221: 29-36.

Marzouki R, Brahmia A, Alsulami Q A, Keshk S MAS, Abdul-Hamid M, Mariusz J, Faouzi Zid, M \& Heinze T. (2021). Structure, thermal stability, and Electrical Properties of Cellulose-6-Phosphate: Development of a Novel Fast Na-ionic Conductor. Accepted to be publish Polymer International.

Mohammad M, Nasiria A, Asadipourc A, Farajia M, Kargar E (2019) A facile and green method for synthesis of ZnFe204@CMC as a new magnetic nano photocatalyst for ciprofloxacin removal from aqueous media. Methodsx 6: 1575-1580.

Mohamed R M, khalid I A, Baeissa E S, Al-Rayyani MA (2012) Photocatalytic Degradation of Methylene Blue by $\mathrm{Fe} / \mathrm{ZnO} / \mathrm{SiO}$ Nanoparticles under Visible light. Journal of Nanotechnology 329082.

Nasrullah A, Bhat A H, Naeem A, Isa M H, Danish M (2018) High surface area mesoporous activated carbon-alginate beads for efficient removal of methylene blue. International journal of biological macromolecules 107: 1792-1799.

Oh W C, Chen M L (2008) Synthesis and characterization of $\mathrm{CNT} / \mathrm{TiO}_{2}$ composites thermally derived from MWCNT and titanium (IV) n-butoxide. Bulletin of the Korean Chemical Society 29: 159-164.

Patil R P, Delekar SD, Mane D R, Hankare P P (2013) Synthesis, structural and magnetic properties of different metal ion substituted nanocrystalline zinc ferrite. Results in Physics, 3: 129-133.

Paul D R, Sharma R, Nehra SP, Sharma A (2019) Effect of calcination temperature, pH and catalyst loading on photodegradation efficiency of urea derived graphitic carbon nitride towards methylene blue dye solution. RSC Advances 9: 15381-15391.

Safizade B, Masoudpanah S M, Hasheminiasari M, Ghasemi A (2018) Photocatalytic activity of $\mathrm{BiFeO}_{3} / \mathrm{ZnFe}_{2} \mathrm{O}_{4}$ nanocomposites under visible light irradiation. RSC Advances 13: 6745 -7314.

Salvetat J P, Kulik, AJ, Bonard JM, Andrew G, Briggs D, Stöckli T, Méténier et al (1999) Elastic modulus of ordered and disordered multiwalled carbon nanotubes. Advanced Materials 11: 161-165.

Shahnavaz Z, Lorestani F, Alias Y, Woi P M (2014) Polypyrrole- $\mathrm{ZnFe}_{2} \mathrm{O}_{4}$ magnetic nanocomposite with core-shell structure for glucose sensing. Applied Surface Science, 317: 622-629.

Singhal S, Sharma R, Singh C, Bansal S (2013) Enhanced Photocatalytic Degradation of Methylene Blue Using $\mathrm{ZnFe}_{2} \mathrm{O}_{4} / \mathrm{MWCNT}$ Composite Synthesized by Hydrothermal Method. Indian Journal of Materials 
Science 356025.

Tedjieukeng HMK, Tsobnang P K, Fomekong RL, Etape EP, Joy PA, Delcorte A, Lambi JN (2018) Structural characterization and magnetic properties of undoped and copper-doped cobalt ferrite nanoparticles prepared by the octanoate coprecipitation route at very low dopant concentrations, RSC Advances :, 38621-38630.

Valenzuela M A, Bosch P, Jimenez-Becerrill J, Quiroz, OPaez A I (2002) Preparation characterization and photocatalytic activity of $\mathrm{ZnO}, \mathrm{Fe}_{2} \mathrm{O}_{3}$ and $\mathrm{ZnFe}_{2} \mathrm{O}_{4}$. Journal Photochemical Photobiology A 148: 177-182.

Xu S, Feng D, Shangguan W (2009) Preparations and Photocatalytic Properties of Visible-Light-Active Zinc Ferrite-Doped $\mathrm{TiO}_{2}$. Photocatalyst Journal Physics Chemistry C 113: 2463-2467.

\section{Figures}

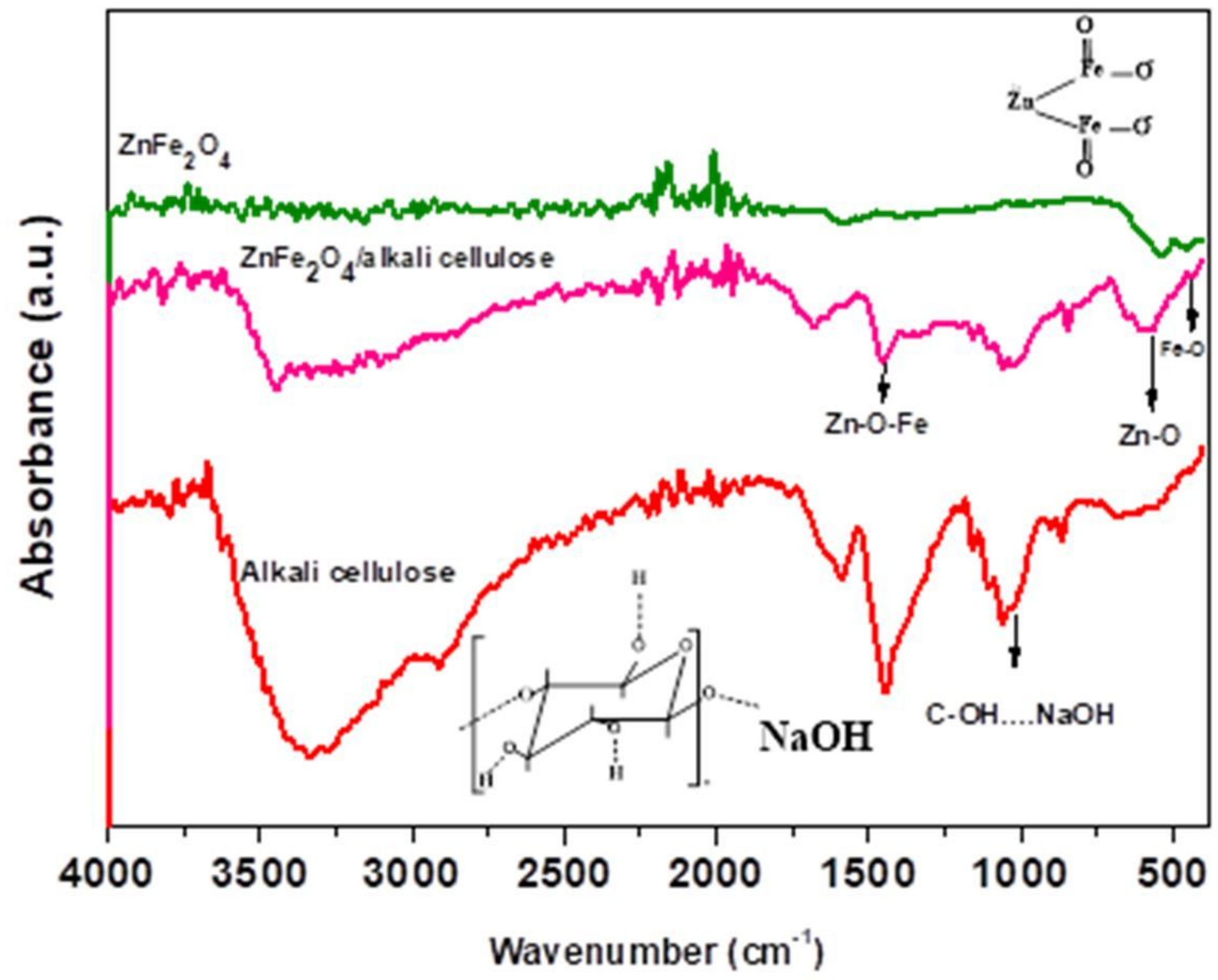


Figure 1

FT-IR spectra of alkali cellulose and its composite. Note: The designations employed and the presentation of the material on this map do not imply the expression of any opinion whatsoever on the part of Research Square concerning the legal status of any country, territory, city or area or of its authorities, or concerning the delimitation of its frontiers or boundaries. This map has been provided by the authors.

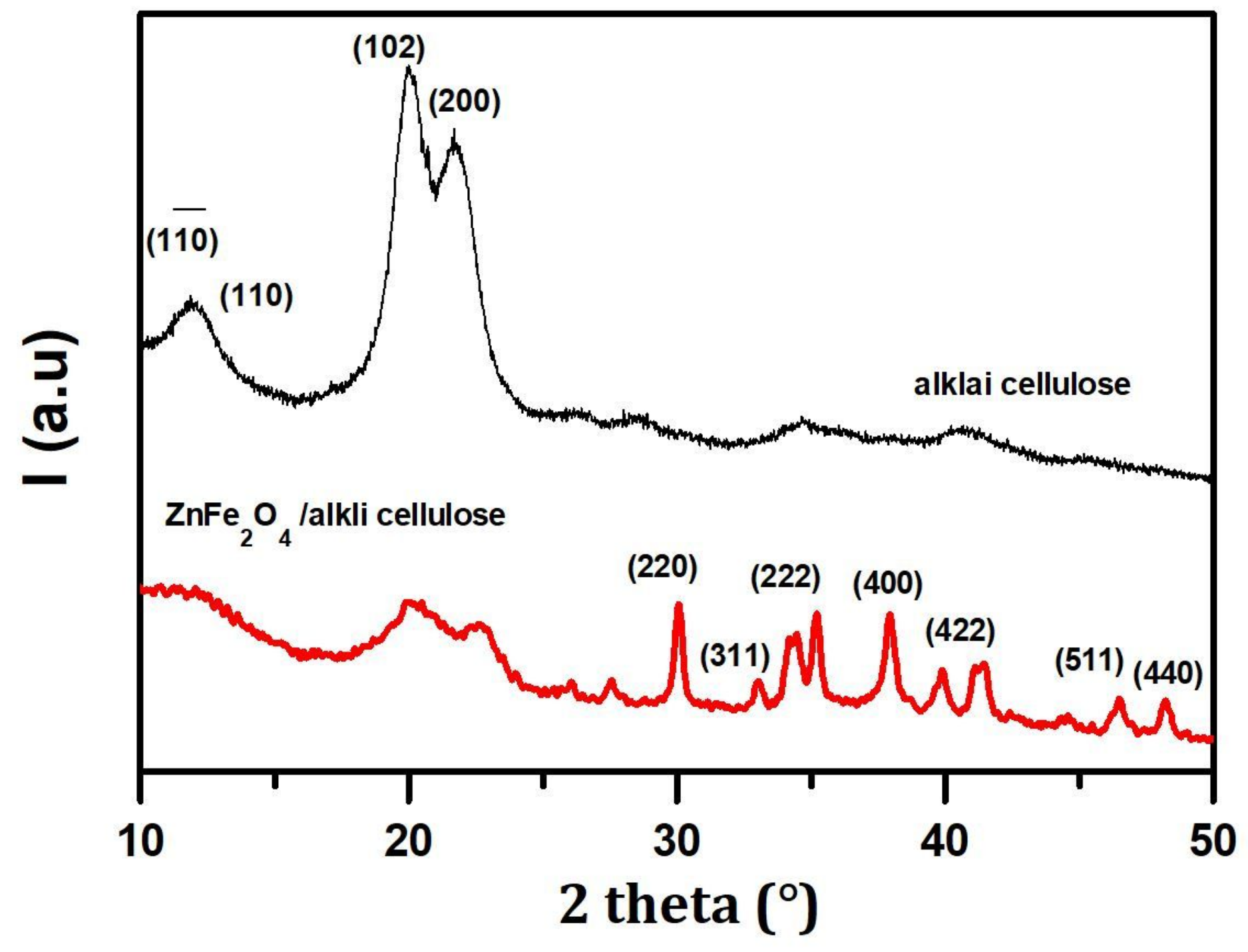

Figure 2

XRD of alkali cellulose and its composite. Note: The designations employed and the presentation of the material on this map do not imply the expression of any opinion whatsoever on the part of Research Square concerning the legal status of any country, territory, city or area or of its authorities, or concerning the delimitation of its frontiers or boundaries. This map has been provided by the authors. 

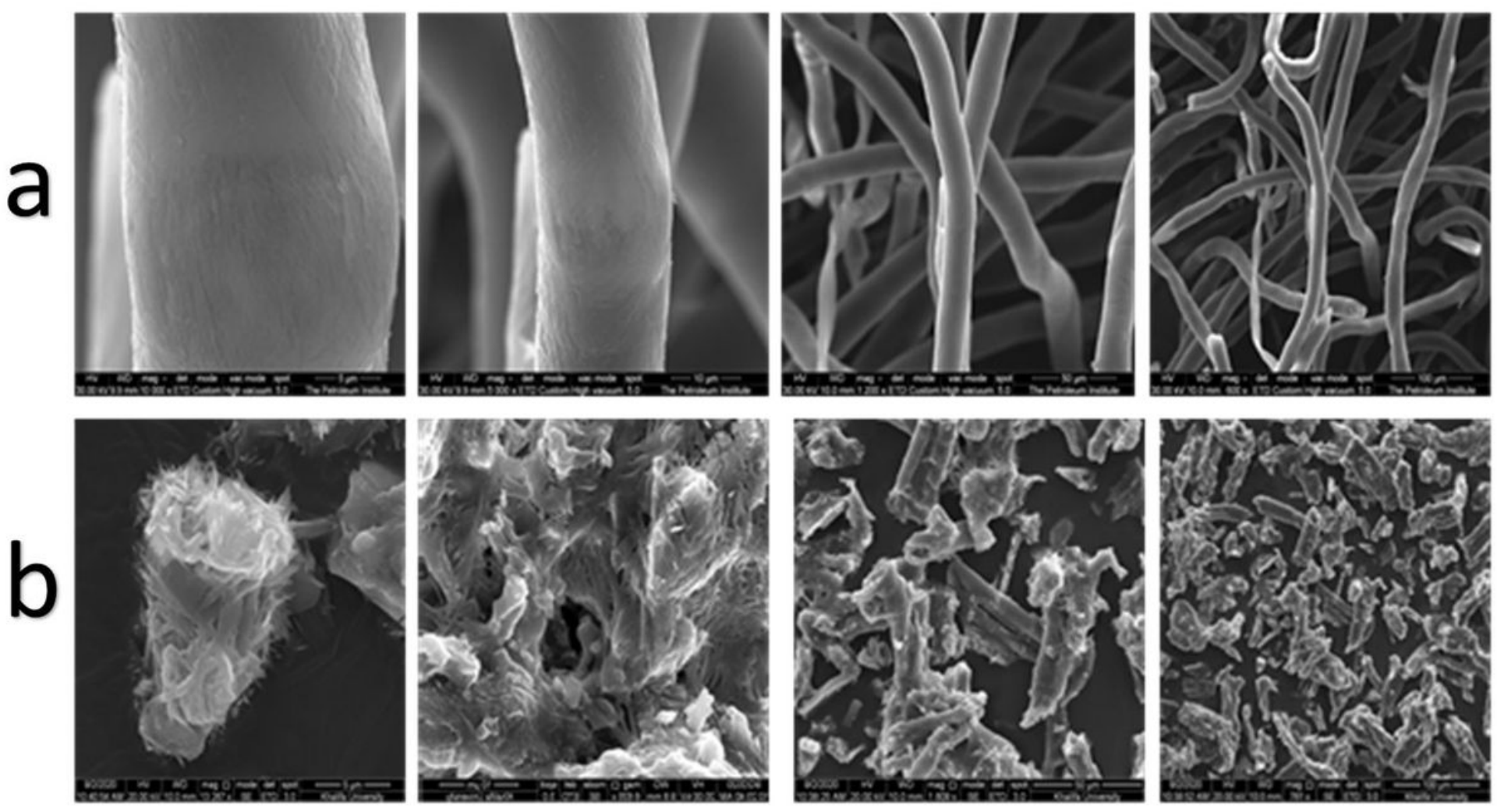

Figure 3

SEM micrographs of (a) alkali cellulose (b) ZnFe204/alkali cellulose. 

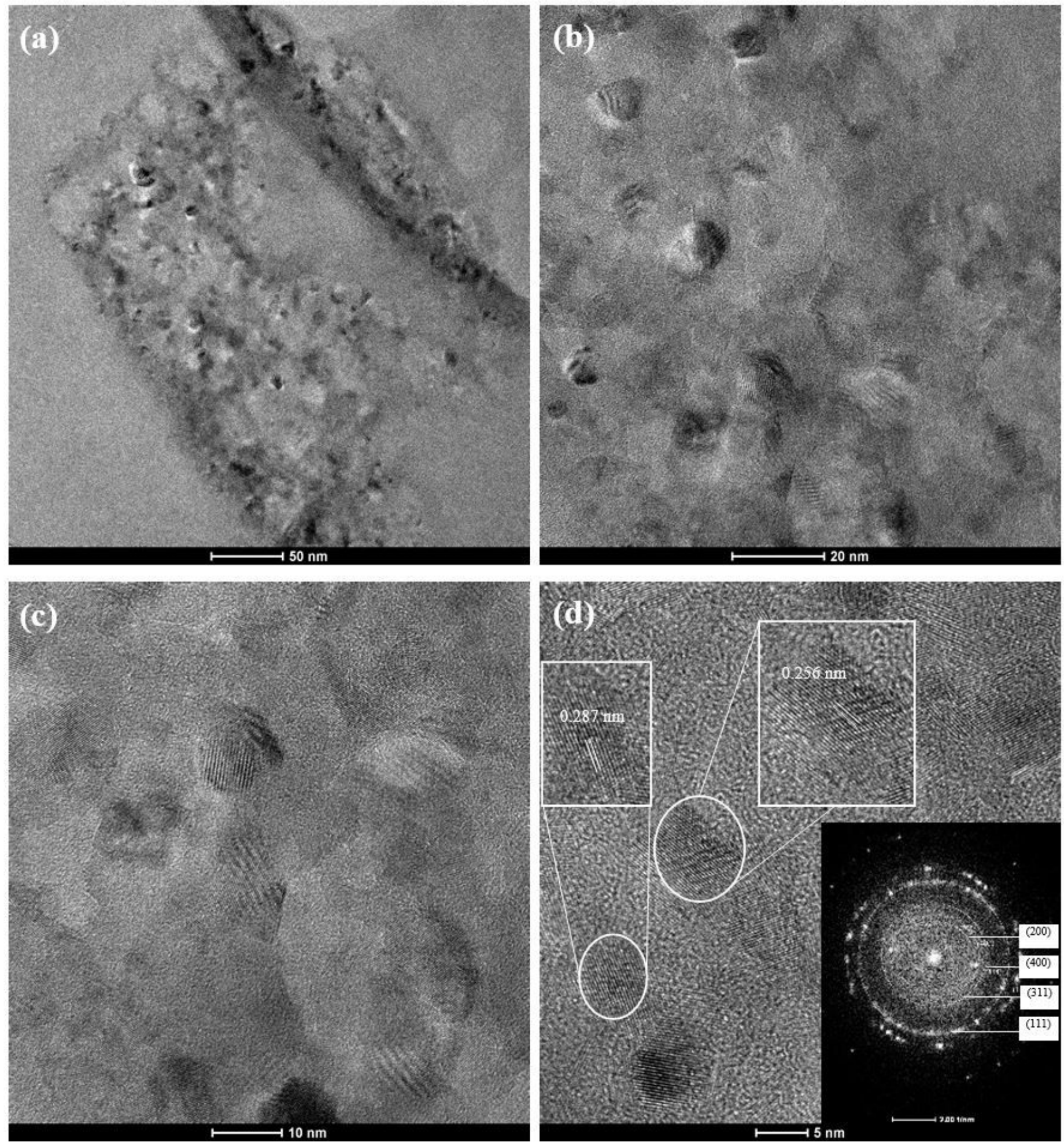

\section{Figure 4}

TEM micrographs of ZnFe204/alkali cellulose. 

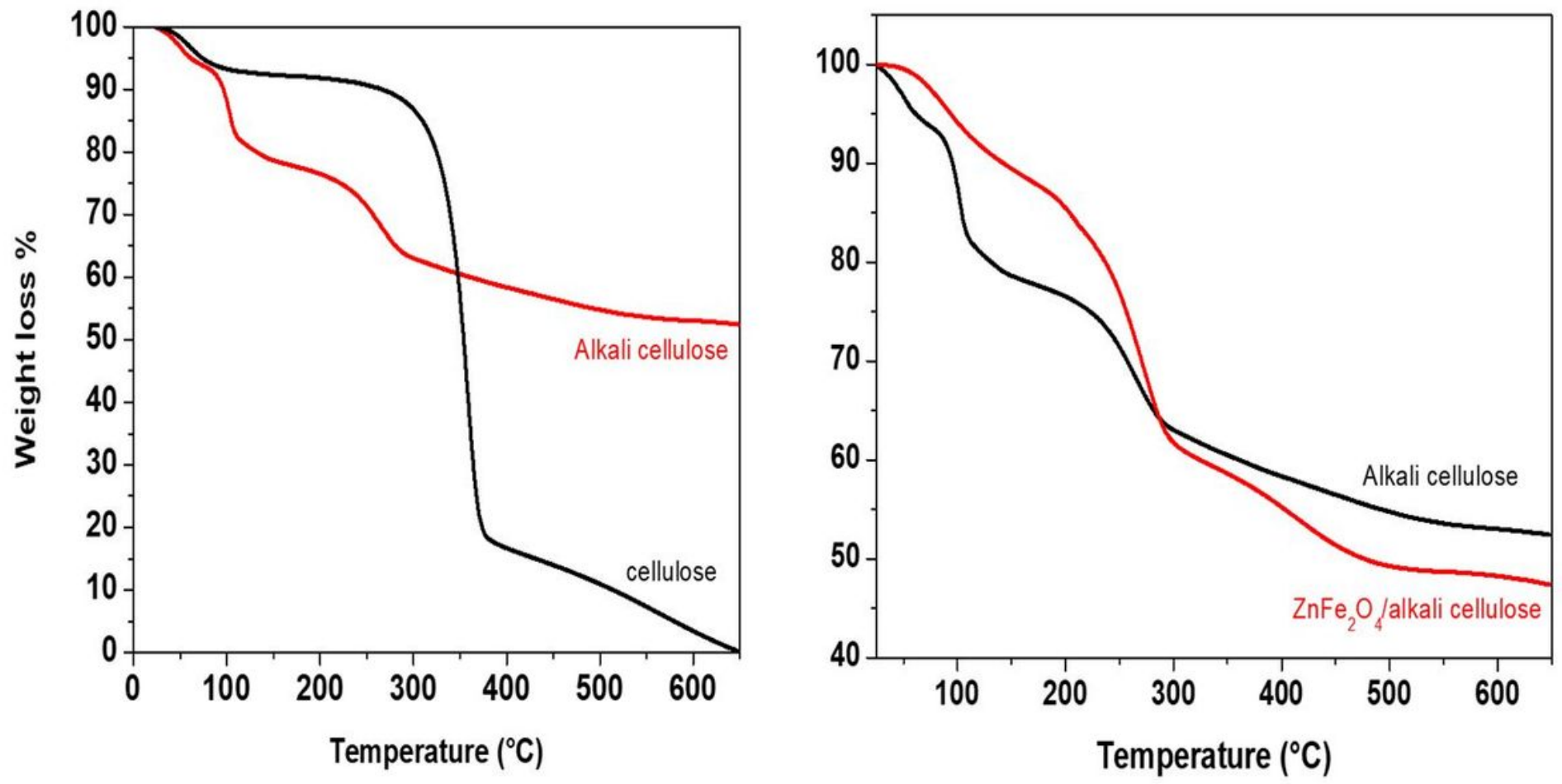

Figure 5

TGA of cellulose, alkali cellulose, ZnFe204/alkali cellulose. 


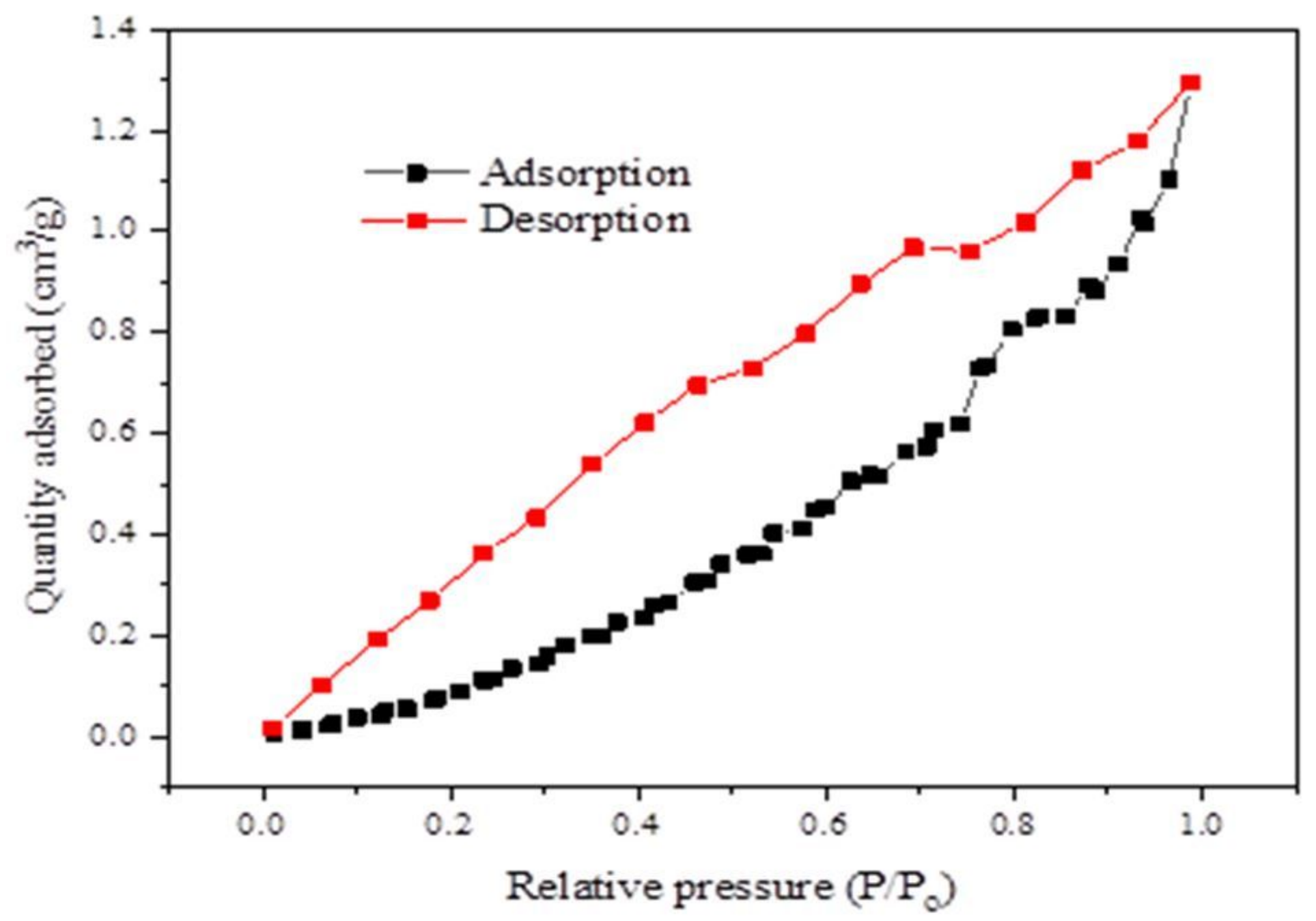

Figure 6

BET N2 adsorption-desorption isotherm of ZnFe204/alkali cellulose.
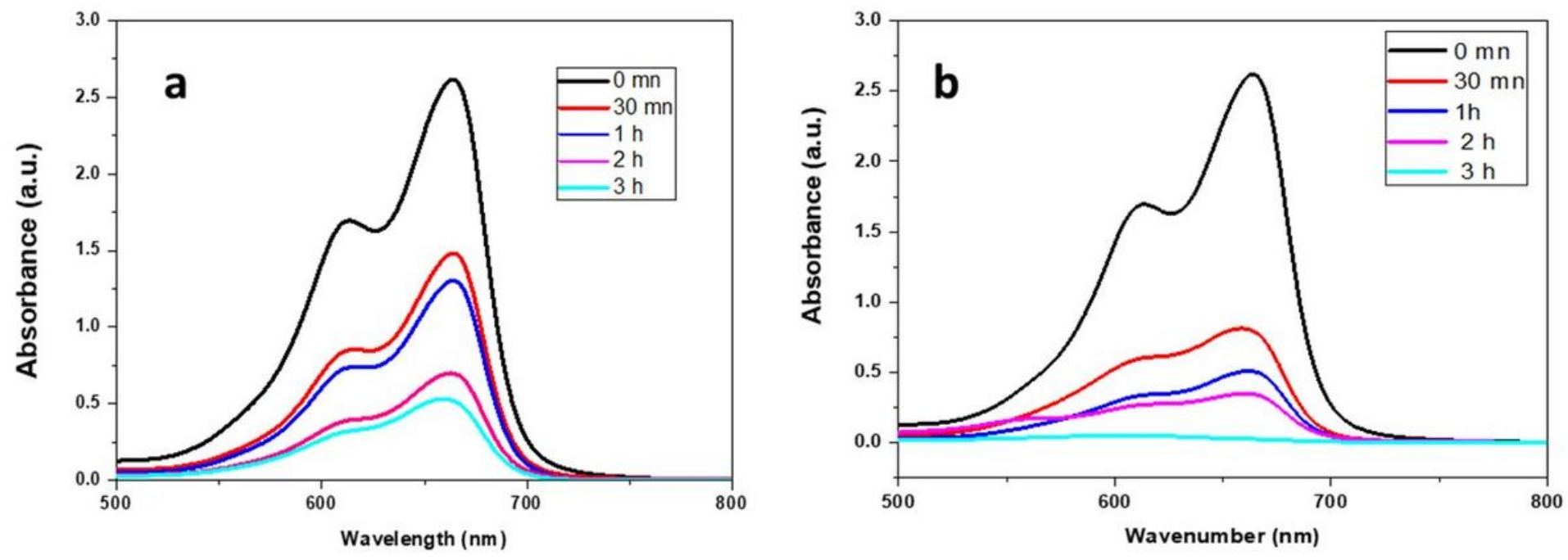

Figure 7 
Variation in the UV-visible absorbance of MB under the effect of sunlight: (a) ZnFe204/cellulose (b) ZnFe204/alkali-cellulose.

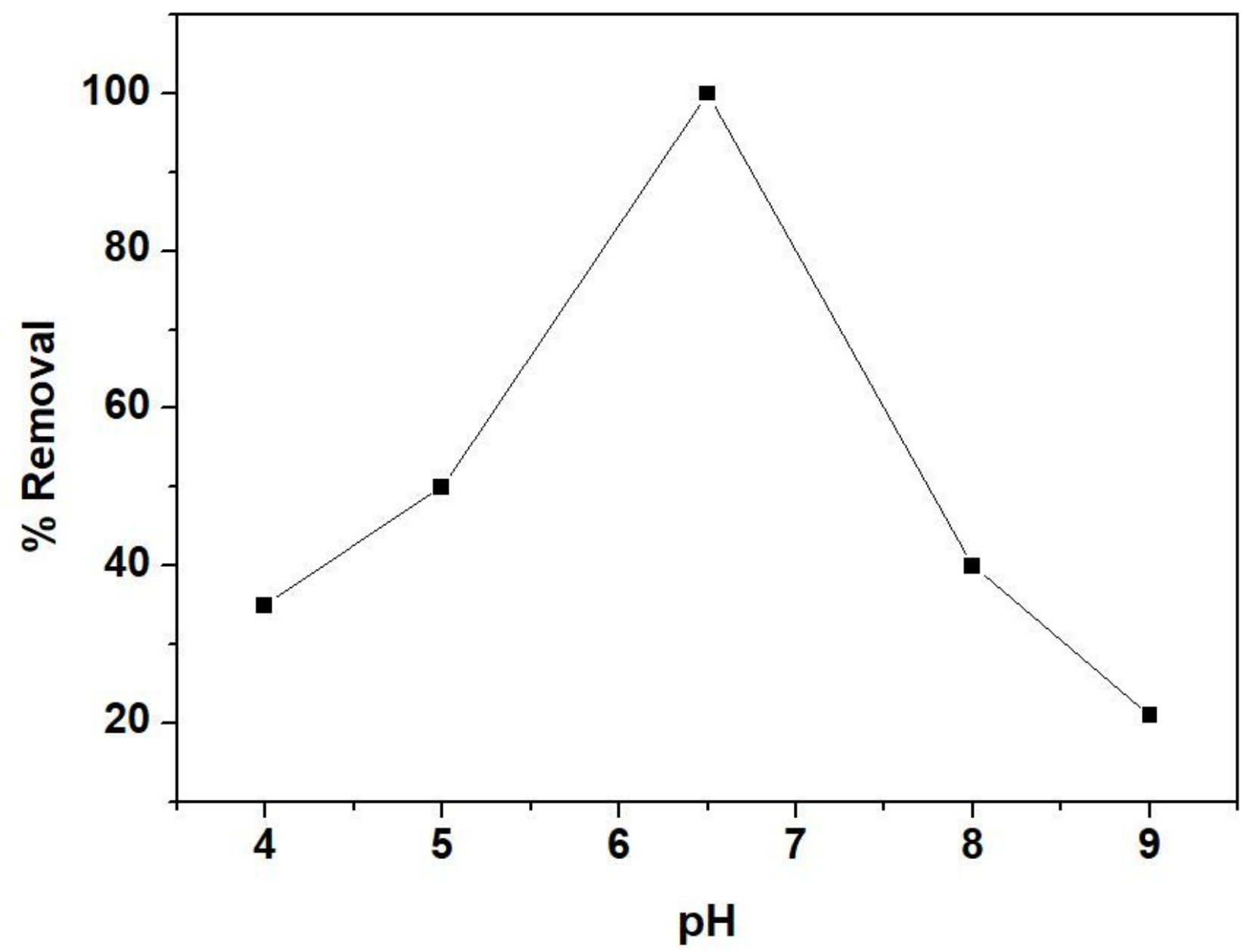

Figure 8

The effect of $\mathrm{pH}$ solution in\% degradation of MB under the effect of sunlight. 